\title{
What is the evidence for the use of parenteral nutrition (PN) in critically ill surgical patients: a systematic review and meta-analysis
}

\author{
K. Ledgard ${ }^{1} \cdot$ B. Mann ${ }^{1} \cdot$ D. Hind ${ }^{2} \cdot$ M. J. Lee ${ }^{1,3}$
}

Received: 30 May 2018 / Accepted: 8 November 2018 / Published online: 14 November 2018

(c) The Author(s) 2018

\begin{abstract}
Background Malnutrition is associated with poor outcomes in surgical patients and corrective enteral feeding may not be possible. This is a particular problem in the acute setting where malnutrition is prevalent. The aim of this systematic review was to evaluate the use of parenteral nutrition (PN) in critically ill surgical patients.

Methods This review was registered with PROSPERO (CRD42017079567). Searches of the CENTRAL, EMBASE, and MEDLINE databases were performed using a predefined strategy. Randomised trials published in English since 1995, reporting a comparison of PN vs any comparator in a critically ill surgical population were included. The primary outcome was mortality. Risk of bias was assessed using the Cochrane risk of bias tool and the Grading of Recommendations Assessment, Development and Evaluation assessment. Meta-analysis was performed using a random effects model to assess variation in mortality and length of stay.

Results Fourteen RCTs were identified; standard PN was compared vs other forms of PN in ten studies, to PN with variable dose amino acids in one, and to enteral nutrition (EN) in three. In trials comparing glutamine-supplemented PN (PN-GLN) to $\mathrm{PN}$, a non-significant reduction in mortality was noted (risk difference -0.08 . 95\% CI $-0.17,0.01, p=0.08$ ). A trend for a reduction in length of stay was seen in PN-GLN to PN comparator (mean reduction $-2.4,95 \% \mathrm{CI}-7.19$ to 2.32 days, $I^{2}$ $=92 \%)$. Impact on other outcome measures varied in direction of effect.

Conclusions PN may offer benefit in critically ill surgical patients. The size and quality of studies lead to uncertainty around the estimates of clinical effect, meaning a robust trial is required.
\end{abstract}

Keywords Nutritional support $\cdot$ Surgery $\cdot$ Critical illness $\cdot$ Gastrointestinal failure $\cdot$ Review

K. Ledgard and B. Mann are co-first authors and they contributed equally to the work.

Electronic supplementary material The online version of this article (https://doi.org/10.1007/s10151-018-1875-1) contains supplementary material, which is available to authorized users.

M. J. Lee

m.j.lee@ sheffield.ac.uk

University of Sheffield Medical School, Sheffield, UK

2 School of Health and Related Research, University of Sheffield, Sheffield, UK

3 Department of General Surgery, Northern General Hospital, First Floor, Old Nurses Home, S5 7AU Sheffield, UK

\section{Introduction}

Malnutrition is a well-documented challenge in surgery as it is associated with delayed healing, higher rates of complications and prolonged length of hospital stay [1-3]. A high proportion of patients admitted under the care of gastrointestinal surgeons are at risk of malnutrition, and reaching appropriate caloric intake in the postoperative period is problematic [4]. Most general surgery patients have an element of gastrointestinal failure either due to their primary pathology or due to surgical intervention, and cannot absorb nutrition as needed $[5,6]$. These patients may require support by other methods, which may include intravenous fluids or the use of parenteral nutrition (PN). Problems related to malnutrition and intestinal failure may be compounded further if the patient is admitted to hospital with an acute surgical pathology: the patient may have endured acute gastrointestinal dysfunction or 
failure for a period of time prior to admission and be in nutritional deficit. Current guidance in advocates that $\mathrm{PN}$ is not typically be started until 5-7 days post-surgery unless the patient has high nutritional risk or is in a hypermetabolic state [7-9]. The same guidance acknowledges that it is based upon low-to-moderate quality evidence.

There is a significant body of literature on the use of PN in the critical care setting [10]. Unfortunately, this cannot be easily translated to the general surgical population as it includes a large number of patients with non-surgical diagnoses. This population is unlikely to have the same degree of gastrointestinal dysfunction (mechanical or otherwise) as the gastrointestinal surgical population. $\mathrm{PN}$ has been established in elective perioperative nutrition for 25 years [11]; however, recent work evaluating its use in acute surgical admissions has shown variation in practice [12]. One reason for this may be an incomplete evidence base.

The aim of this study was to conduct a systematic review and meta-analysis to evaluate the effect of PN in critically ill gastrointestinal surgery patients with respect to mortality, length of stay and other complications of care.

\section{Materials and methods}

\section{Protocol and registration}

This review was conducted in accordance with the COCHRANE handbook [13], and reported with reference to the Preferred Reporting Items for Systematic Reviews and Meta-Analyses (PRISMA) guidelines [14]. It was prospectively registered on the PROSPERO database (CRD42017079567).

\section{Eligibility criteria}

Eligible studies were randomised controlled trials (RCTs) published in English, after 1995. For inclusion, the studies had to report outcomes of critically ill surgical patients. The patient group was defined as those requiring intensive care admission following elective or emergency abdominal gastrointestinal surgery (e.g. laparotomy, colorectal resection). Studies were eligible where they compared any form of PN to another form of PN, PN with enteral nutrition (EN), EN alone, placebo, or no nutrition intervention.

Excluded studies were those in which patients had elective preoperative feeding, paediatric cases, conditions treated by surgeons which do not require surgical interventions (e.g. pancreatitis) or trials involving packaged interventions. Studies reporting trauma populations were excluded.

\section{Outcomes}

The primary outcome was mortality. Secondary outcomes were hospital length of stay (LOS), hospital acquired infections (HAIs), nitrogen balance and weight change.

\section{Information sources}

Searches were performed of the Cochrane Central Register of Controlled Trials (CENTRAL) in the Cochrane Library (all time), MEDLINE (Ovid SP) from 1946 to September 2017 and Embase (Ovid SP) from 1974 to September 2017, which used no limits and combined Boolean operators, free text terms and thesaurus terms, no language or date limitation was applied. The search strategies used are given in Appendix 1 in Supplementary material. Additional citations were identified through expert recommendations and hand-searching of citations.

\section{Study selection}

Search results were imported into a citation management program (Covidence.org) and duplicates removed. Two investigators independently screened articles for eligibility against predefined exclusion criteria at the title/abstract and full-text stage; conflicts were resolved by a discussion with a third investigator.

\section{Data extraction}

Data were extracted into predefined tables by two reviewers and compared, with disagreements resolved as above. The following items were recorded: author, year, study design, basic population demographics, intervention and control arms, primary outcomes, and secondary outcomes including LOS, weight change, mortality at 6 months, mortality within the hospital admission, HAIs, complications and nitrogen balance. Nitrogen balance is a method used to estimate protein balance. Critically ill patients are typically in a catabolic state and will have a negative nitrogen balance (i.e. protein intake is not adequate). A positive or neutral balance shows that needs are being met or exceeded [15].

\section{Risk of bias of individual studies}

The Cochrane Risk of Bias tool was used independently by two authors to assess bias of relevant studies [13]. 


\section{Summary measures}

The summary methods for results obtained varied, but included population means with standard errors, differences, ratios, binary results with confidence ratios and tests of significance.

\section{Synthesis of results}

Pre-planned meta-analysis using a random effects model was used to assess risk difference for mortality, and mean difference for length of stay with Revman v5.3 software (Cochrane Collaboration, Copenhagen).

\section{Risk of bias across studies}

Using the GRADE PRO tool, bias was assessed across the studies for the primary outcome of death, within all comparators [16].

\section{Results}

\section{Study selection}

The search identified 2638 references (Fig. 1). Following the removal of duplicates, 1636 papers, were screened for inclusion. Eighty-six papers were reviewed at full text, and 14 of them were included in the review. Seventy-two were rejected at this stage for the following reasons: no PN comparator $(n=28)$, non-emergency population $(n=25)$, article in not in the English language $(n=8)$, no placebo comparator $(n=2)$, ineligible comparator $(n=2)$, ineligible intervention $(n=2)$, ineligible patient population $(n=2)$, ineligible study design $(n=2)$, published before $1995(n=1)$.

\section{Study characteristics}

The included studies included ten trials comparing standard PN against a supplemented PN [1, 17-25]; three trials comparing PN against EN [26-28], one of which also compared $\mathrm{PN}$ to no nutrition intervention [26] and one trial comparing

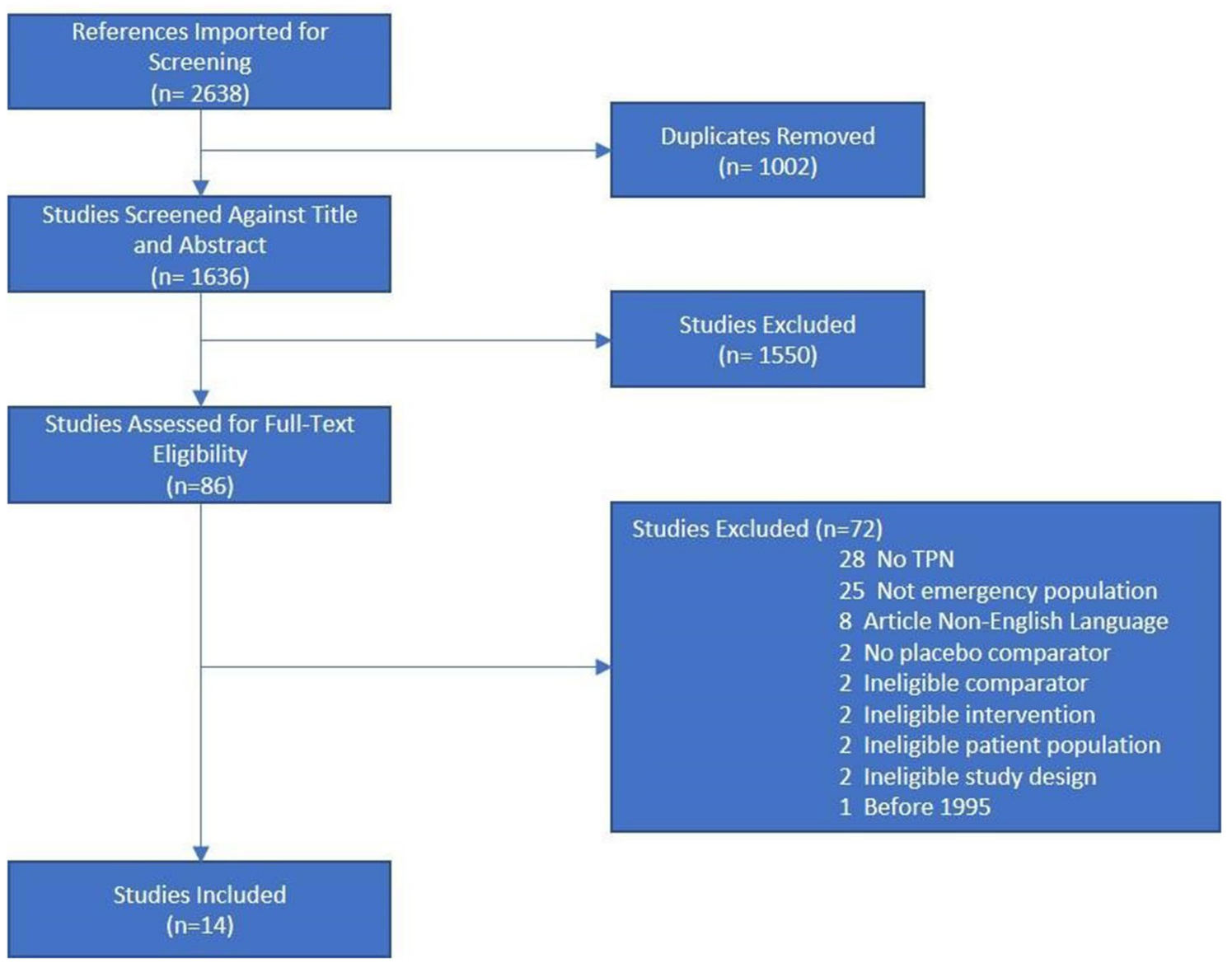

Fig. 1 PRISMA flow diagram 
PN to PN with variable doses of amino acids based upon blood tests [29] (Table 1/Fig. 2).

Four studies reported mortality [18, 19, 22, 25, 27], some within hospital others at 6-month follow-up, those with the same intervention and control arms have been meta-analysed below; seven trials reported new-onset or hospital-acquired infections $[1,18,21,22,25,27,28]$; seven trials reported length of stay $[18,19,21,22,25,27,28]$, and four trials reported nitrogen balance [21, 24, 27, 29] (Table 2). A summary of all reported outcomes is presented in Table S1.

\section{Risk of bias within studies}

Two studies had high risk and six an unclear risk of bias from the sequence generation method. Three studies had a high and seven an unclear risk of bias from the allocation concealment method. Five trials had high-risk methods of blinding patients and clinicians, half had a low risk. Six studies had high-risk blinding of assessments and two studies were unclear. No study had a high risk

Table 1 Summary of study characteristics

\begin{tabular}{|c|c|c|c|c|}
\hline Author (year) & Population & $\begin{array}{l}\text { Total } \\
\text { popula- } \\
\text { tion }(N)\end{array}$ & Intervention & Control \\
\hline Ahrens (2005) [1] & $\begin{array}{l}\text { Consecutive patients requiring } \\
\text { parenteral nutrition in a level I } \\
\text { trauma centre }\end{array}$ & 40 & Low-calorie PN & Standard-calorie PN \\
\hline Antebi (2003) [17] & $\begin{array}{l}\text { ICU patients undergoing major } \\
\text { abdominal surgery }\end{array}$ & 20 & SMOF PN regimen & LIPOVEN PN regimen \\
\hline Berard (2002) [29] & $\begin{array}{l}\text { Surgical intensive care patients } \\
\text { (SICU), requiring PN for } 10 \\
\text { days }\end{array}$ & 13 & $\begin{array}{l}5 \text { day } \mathrm{PN} \text { as standard, } 5 \text { days } \mathrm{PN} \\
\text { individualised }\end{array}$ & 10-day PN \\
\hline Chen (2017) [28] & $\begin{array}{l}\text { Confirmed gastric outlet obstruc- } \\
\text { tion patients }\end{array}$ & 68 & PN 7 days preoperatively & $\begin{array}{l}\text { Increasing EN } 14 \text { days before } \\
\text { surgery }\end{array}$ \\
\hline Estivariz (2008) [18] & $\begin{array}{l}\text { Pancreatitic and non-pancreatitic } \\
\text { surgical intensive care patients } \\
\text { requiring PN }\end{array}$ & 59 & GLN-PN & GLN-free PN \\
\hline Goeters (2002) [19] & Post-operative intensive care unit & 163 & Al-Gln-supplemented PN & GLN-free PN \\
\hline $\mathrm{Hu}(2003)[26]$ & $\begin{array}{l}\text { Post-operative patients with } \\
\text { impaired liver function (Child } \\
\text { B or C) }\end{array}$ & 35 & PN or EN (via jejunostomy) & No nutritional intervention \\
\hline Hulsewe (2004) [20] & $\begin{array}{l}\text { Nutritionally depleted gastroin- } \\
\text { testinal surgery patients }\end{array}$ & 24 & $\begin{array}{l}\text { Glycyl-glutamine supplemented } \\
\text { PN }\end{array}$ & Isonitrogenous control solution $\mathrm{PN}$ \\
\hline Jiang (1999) [21] & $\begin{array}{l}\text { Major gastrointestinal surgery } \\
\text { patients requiring PN for } 6 \text { days }\end{array}$ & 120 & Al-Gln supplemented PN & GLN-free PN \\
\hline Luo (2008) [23] & Surgical intensive care patients & & GLN-PN & GLN-free PN \\
\hline Malhotra (2004) [27] & $\begin{array}{l}\text { Emergency surgery for peritonitis } \\
\text { following gut perforation }\end{array}$ & 169 & $\mathrm{PN}$ & EN (NG feed) \\
\hline Powell-Tuck (1999) [22] & $\begin{array}{l}\text { Patients requiring } \mathrm{PN} \text {, surgical } \\
\text { subgroup reported }\end{array}$ & 168 & GLN-PN & PN \\
\hline Wang (2003) [24] & $\begin{array}{l}\text { Major abdominal Surgery includ- } \\
\text { ing trauma }\end{array}$ & 40 & PN with BCAA & PN with AA \\
\hline Ziegler (2016) [18] & $\begin{array}{l}\text { Surgical intensive care patients } \\
\text { requiring PN }\end{array}$ & 150 & GLN-PN & Standard PN \\
\hline
\end{tabular}

$P N$ parenteral nutrition, $E N$ enteral nutrition, $A l$ alanine, $G L N-P N$ glutamine-supplemented PN 
Table 2 Study comparators and outcomes

\begin{tabular}{|c|c|c|c|c|c|}
\hline & $\begin{array}{l}\text { In-hospital } \\
\text { mortality }\end{array}$ & $\begin{array}{l}\text { Length of } \\
\text { stay }\end{array}$ & HAI & $\begin{array}{l}\text { Weight } \\
\text { change }\end{array}$ & $\begin{array}{l}\text { Mechanistic data, } \\
\text { e.g. nitrogen balance }\end{array}$ \\
\hline \multicolumn{6}{|l|}{ PN vs EN } \\
\hline Malhotra [27] & $\checkmark$ & $\checkmark$ & $\checkmark$ & $\checkmark$ & $\checkmark$ \\
\hline Chen [28] & - & $\checkmark$ & $\checkmark$ & $\checkmark$ & - \\
\hline Hu [26] & - & - & - & $\checkmark$ & $\checkmark$ \\
\hline \multicolumn{6}{|l|}{ PN-GLN vs PN } \\
\hline Estivariz [18] & $\checkmark$ & $\checkmark$ & $\checkmark$ & - & - \\
\hline Goeters [19] & $\checkmark$ & $\checkmark$ & - & - & - \\
\hline Jiang [21] & - & $\checkmark$ & $\checkmark$ & - & $\checkmark$ \\
\hline Powell-tuck [22] & $\checkmark$ & $\checkmark$ & $\checkmark$ & - & $\checkmark$ \\
\hline Ziegler [25] & $\checkmark$ & $\checkmark$ & $\checkmark$ & - & $\checkmark$ \\
\hline Hulsewe [20] & - & - & - & $\checkmark$ & $\checkmark$ \\
\hline Luo [23] & - & - & - & $\checkmark$ & $\checkmark$ \\
\hline \multicolumn{6}{|l|}{ PN vs standard care } \\
\hline Berard [29] & - & - & - & - & $\checkmark$ \\
\hline $\mathrm{Hu}[26]$ & - & - & - & - & $\checkmark$ \\
\hline \multicolumn{6}{|c|}{ BCAA-PN vs PN-AA } \\
\hline Wang [24] & - & - & - & - & $\checkmark$ \\
\hline \multicolumn{6}{|c|}{ SMOF-PN vs Lipoven } \\
\hline Antebi [17] & - & - & - & - & $\checkmark$ \\
\hline \multicolumn{6}{|c|}{ Low calories PN vs standard calories PN } \\
\hline Ahrens [1] & - & - & $\checkmark$ & - & - \\
\hline
\end{tabular}

Tick shows that outcome was assessed for. $H A I$ hospital-acquired infections, $P N$ parenteral nutrition, $E N$ enteral nutrition, $B C A A$ branched-chain amino acids of incomplete data and two trials were unclear. One trial had a high risk of selective reporting. Five studies had a high risk of other bias and five an unclear risk. Trials with control variables of EN or control (standard nutritional care) are open studies [26, 28]. Many of the trials had no statement of conflict of interest or funding sources while many others were funded by medical intervention manufacturers (Figs. 3, 4).

\section{Synthesis of results}

\section{Mortality}

In the comparison of PN-GLN to PN (4 studies, 413 patients, Fig. 5), GLN-supplemented PN reduced risk of mortality by $8 \%$ (risk difference (RD) $-0.08,95 \%$ CI -0.17 to $0.01, p=0.08$ ), but this was not statistically significant. Statistical heterogeneity was low $\left(I^{2}=22 \%\right)$. The one trial comparing PN to EN did not observe a statistically significant reduction in death (RD $-0.05,95 \%$ CI- 0.17 to $0.06, p=0.37$ ) [27].

\section{Length of hospital stay}

In the comparison of PN to EN, Malhotra showed no significant reduction in LOS (mean difference -0.11 days, $95 \%$ CI -1.17 to $1.39, p=0.085$ ) [27]. Chen provided no confidence intervals; however, found a significant reduction in LOS for the PN group [28]. Meta-analysis comparing the effect of PN-GLN to PN in length of hospital stay (5 studies, 474 patients, Fig. 6) found a trend towards reduced LOS in the glutamine-supplemented group (mean difference -2.4 , $95 \% \mathrm{CI}-7.19$ to 2.32 days). This was associated with high heterogeneity $\left(I^{2}=92\right)$.

\section{Hospital-acquired infections}

Seven studies reported HAI as an outcome. One study comparing low-calorie PN to high-calorie PN, found no significant reduction in HAI [1]. Two studies compared PN to EN $(n=232)$. Chen found a significant increase in HAI with PN, but data are incomplete, preventing further interpretation [28]. Malhotra found a non-significant reduction in HAI with the use of PN (relative risk $=0.66,95 \%$ CI $0.407-1.091$, $p=0.103$ ) [27]. 
Fig. 3 Risk of bias summary

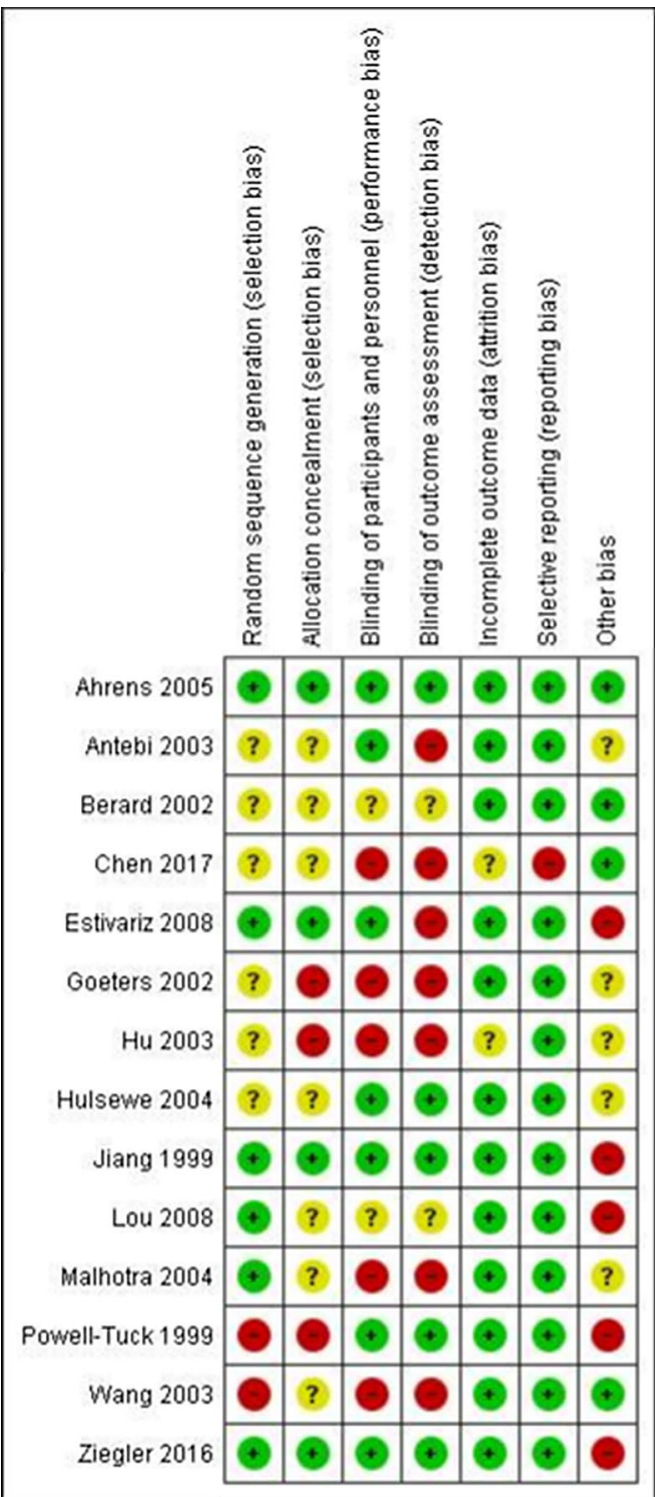

Risk of bias summary: review authors' judgements about each risk of bias item for each included study.

Fig. 4 Risk of bias graph

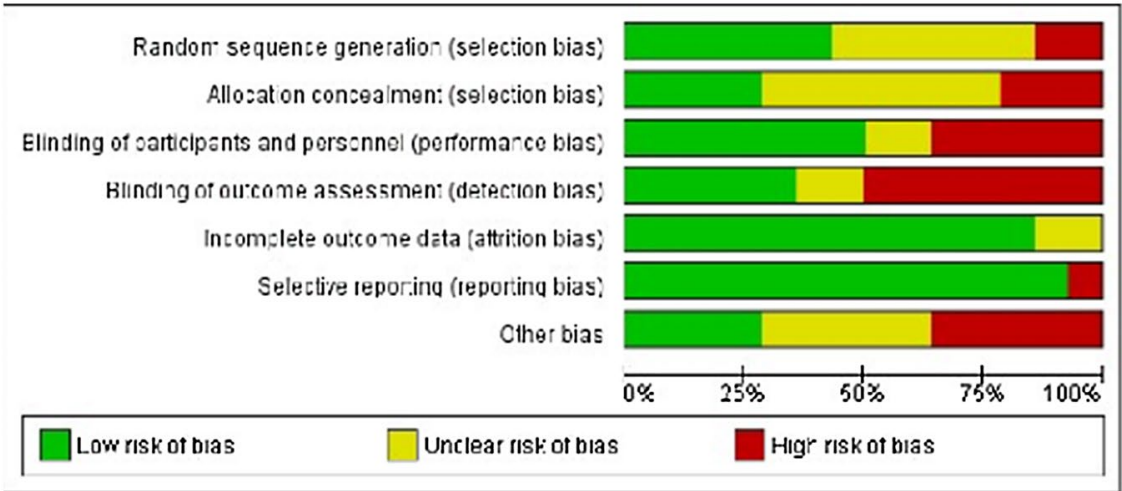

Risk of bias graph: review authors' judgements about each risk of bias item presented as percentages across all included studies. 


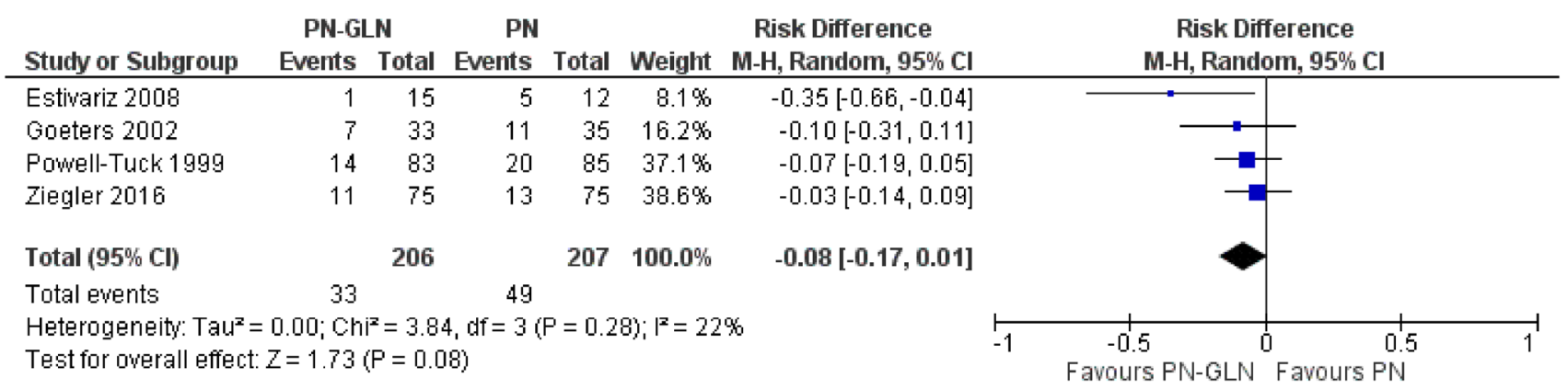

Fig. 5 Meta-analysis of in-hospital mortality, PN-GLN (glutamine-supplemented parenteral nutrition), PN (parenteral nutrition), CI (confidence intervals), and SD (standard deviation)

\begin{tabular}{|c|c|c|c|c|c|c|c|c|c|c|c|c|}
\hline \multirow[b]{2}{*}{ Study or Subgroup } & \multicolumn{3}{|c|}{ PN-GLN } & \multicolumn{3}{|c|}{ PN } & \multicolumn{3}{|c|}{ Mean Difference } & \multirow{2}{*}{\multicolumn{2}{|c|}{$\begin{array}{l}\text { Mean Difference } \\
\text { IV, Random, } 95 \% \mathrm{Cl}\end{array}$}} & \\
\hline & Mean & SD & Total & Mean & SD & Total & Weight & IV, Random, 95\% Cl & & & & \\
\hline Estivariz 2008 & 20 & 2 & 15 & 30 & 6 & 12 & $22.8 \%$ & $-10.00[-13.54,-6.46]$ & & $\longrightarrow$ & & \\
\hline Goeters 2002 & 46 & 49.1 & 33 & 39.4 & 31.1 & 35 & $4.8 \%$ & $6.60[-13.07,26.27]$ & & & & \\
\hline Jiang 1999 & 12.5 & 5.1 & 83 & 16.4 & 7.1 & 81 & $25.1 \%$ & $-3.90[-5.80,-2.00]$ & & - & & \\
\hline Powell-Tuck 1999 & 37.5 & 8.6 & 35 & 37.5 & 8.6 & 30 & $21.7 \%$ & $0.00[-4.19,4.19]$ & & & & \\
\hline Ziegler 2016 & 20 & 4 & 75 & 18 & 5.2 & 75 & $25.5 \%$ & $2.00[0.52,3.48]$ & & & $-\square$ & \\
\hline Total $(95 \% \mathrm{Cl})$ & & & 241 & & & 233 & $100.0 \%$ & $-2.44[-7.19,2.32]$ & & & & \\
\hline $\begin{array}{l}\text { Heterogeneity: Tauz } \\
\text { Test for owerall effect }\end{array}$ & $\begin{array}{l}22.50 ; 0 \\
z=1.01\end{array}$ & $\begin{array}{l}h i^{2}=5 \\
(P=0\end{array}$ & $\begin{array}{l}50.23,0 \\
0.31)\end{array}$ & $f=4(P$ & $=0.00$ & $0001) ; l^{2}$ & $=92 \%$ & & -2 & $\begin{array}{l}-10 \\
\text { Favours PN-GLN }\end{array}$ & $\begin{array}{l}10 \\
\text { Favours PN }\end{array}$ & 20 \\
\hline
\end{tabular}

Fig. 6 Meta-analysis of length of stay, PN-GLN (glutamine-supplemented parenteral nutrition), PN (parenteral nutrition), CI (confidence intervals), SD (standard deviation)

\section{Nitrogen balance}

Five studies reported nitrogen balance, two of which compared PN to no-nutritional intervention $(n=83)$. Berard reported no significance, with no confidence intervals given [29]; $\mathrm{Hu}$ reported a significant improvement but with no confidence intervals [26]. Two studies compared PN to EN $(n=269)$, Malhotra found a significant benefit with PN (88\% population difference, $p<0.05$ ) [27]; Hu found a significant benefit with EN [26], but neither gave confidence intervals. One study comparing PN with branched-chain amino acids (BCAA) and PN with amino acids $(n=40)$ found patients achieved positive nitrogen balance significantly quicker in the BCAA-supplemented group, confidence intervals not given $(p<0.05)$ [24].

\section{Weight change}

Four studies reported on weight change. Three studies compared PN to EN ( $n=337)$ : Chen made no statistical comparison between the interventions [28]; Hulsewe reported no significant result and gives no data [20]; Hu reported no significant difference between groups (mean difference $-0.3 \mathrm{~kg}$ ) [26]; Malhotra found a significant reduction in weight loss with PN (mean difference $=2 \mathrm{~kg}, 95 \% \mathrm{CI}-1.54$ to 2.46 , $p<0.0001$ ) [27]. One study comparing $\mathrm{PN}$ to no-nutrition intervention $(n=70)$ reported a significant difference without confidence intervals (PN mean weight loss $-2.4 \pm 1.1 \mathrm{~kg}$, control $-3.3 \pm 1.7, p<0.05$.) [26]. Malhotra reported a greater weight loss in the intervention group than control $(p<0.05)$ [27]; however, this study included patients with faecal peritonitis who may have been more critically ill than those in any other study included.

\section{Risk of bias across studies}

For the outcome of death, GRADE assessment found the risk of bias across studies comparing PN-GLN to PN to be high. This was due to a lack of allocation concealment information, and imprecision in results. In trials comparing PN to EN, there is a high risk of bias as due to the methodology of being an open trial, they cannot be blinded. A number of other concerns were noted including small population sizes, and the roles of funding sources [30]. The GRADE assessment is presented in Table 3.

\section{Discussion}

This review suggests there may be benefit from the use of PN in the critically ill surgical patient with gastrointestinal failure, in terms of reduced LOS. The effect of PN 


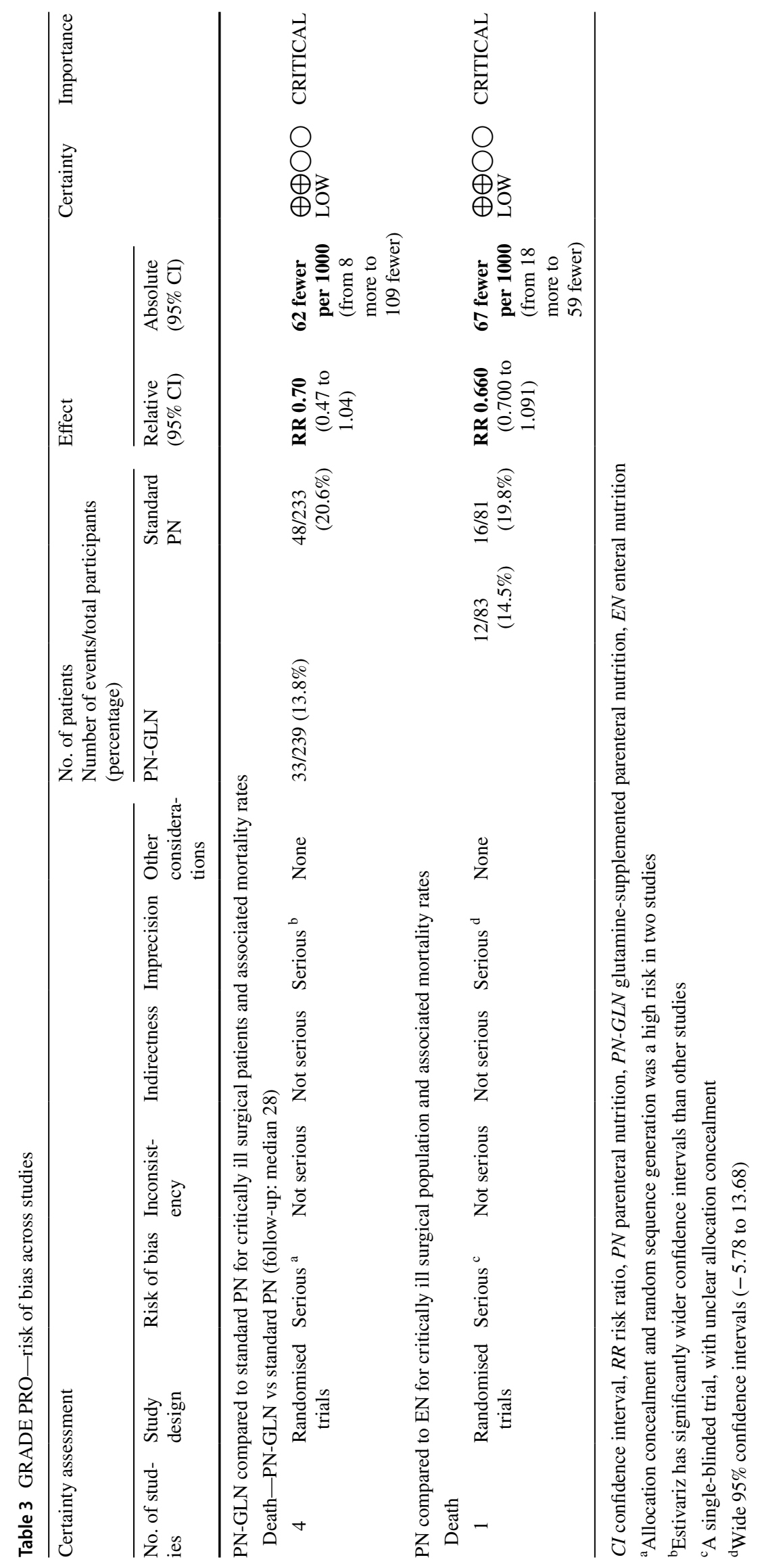


on HAIs is not clear, and there is no clear mortality benefit. The literature is based upon small trials with a high level of heterogeneity and bias and should be interpreted accordingly. There is, however, signal that some forms of PN may offer benefits to the critically ill surgical patient.

The body of literature addressing nutritional support in acutely ill surgical patients is limited; it includes many heterogenous populations, small trials, with heterogeneity of interventions and outcomes. This makes robust assessment challenging. Critically, there are few, if any, trials of PN vs no nutritional support or placebo control, making it difficult to estimate the absolute benefit of nutritional intervention in this setting. Trials of PN in the intensive care population have failed to show consistent significant benefit [31], although these trials included patients with functioning gastrointestinal tracts/non-surgical patients where enteral nutrition might be preferable. A recent pilot trial signalled that the surgical subgroup of patients may derive greater benefit from PN-based interventions than medical comparators [32]. The evidence base is also limited as recruitment to trials in the emergency surgical setting can be challenging-further thought is needed on how best to tackle this problem, otherwise we may not be able to tease out the true effect of nutritional support in the critically ill surgical patient. This study focussed on the role of PN in patients following surgery, and not in the treatment of patients with complications such as anastomotic leak or enterocutaneous fistula, where its role is more defined [6].

The effect of interventions on mortality suggests a modest benefit of PN, particularly glutamine-supplemented $\mathrm{PN}$. This is mechanistically plausible as PN may arrest the catabolic phase and provide calories avoiding cellular exhaustion [33]. Our finding of a potentially reduced LOS is at odds with some reviews [34], although studies of patients in intensive care have shown benefit in PN reducing LOS [35]. Preoperative PN has a known association with shorter postoperative LOS in elective patients [36]. Additional benefits for PN-GLN may come from the antioxidant properties of glutamine as a substrate for synthesis of glutathione [37, 38], and its reported role in preservation of the intestinal epithelial barrier through enterocyte nutrition [39]. Additionally, glutamine is also a substrate for gluconeogenesis in the liver and may support mobilisation of energy reserves [40]. Reviews of recent trials have challenged the benefit of glutamine supplementation [41], and it has fallen out of favour to some extent [42]. In variance with the intensive care literature, the consistent benefit of glutamine supplementation of PN is seen in other acute surgical conditions such as acute pancreatitis (which was not included in this study) [43]. This may suggest that glutamine offers benefits to patients with gastrointestinal pathology, perhaps from the proposed benefits for enterocytes. Alternatively, there may be fundamental differences in the design, conduct, and outcome measures used in the different trials which guide us to incorrect conclusions.

Qualitative assessment of the association between nutritional intervention and HAIs suggests a possibility of benefit. Unfortunately, as varying outcomes and definitions were used across studies, we were unable to pool these data for meta-analysis. A reduction in HAIs is a plausible effect as there is evidence linking infections with acute malnutrition due to the inadequate response of the immune system [44]. This correlates with other reviews and studies reviewing malnutrition in intensive care populations, in elderly populations and in cancer patients where malnutrition is common [45-48].

Current guidelines advocate the use of EN where possible in surgical patients, where they are able to tolerate feed and do not have contraindications such as perforation, fistula or ischaemia $[6,9]$. They advise the use of PN in patients who have been without enteral nutrition for 5-7 days, with hypermetabolic state or significant malnutrition, and also where there is likely to be a significant duration of parenteral therapy ( $>7$ days) $[7,9]$. There is moderate-to-low evidence supporting the use of supplements such as fish oils or arginine for their immunomodulation properties in postoperative patients [9]. As previously, it is important to note that most of this evidence comes from either medical intensive care or patients undergoing elective surgery, so generalisability may be limited.

Special consideration must be given to the effect of hyperglycaemia in critical illness. This may be observed during therapy with PN, and the associated hyperglycaemia has been shown to cause significantly higher rates of morbidity in the intensive care population [49]. The study reporting this finding was published in 2006. All but one study in this review were published before this date, and glycaemic management, therefore, may not have been optimal. This is one change in practice that might alter the findings if some of these studies were repeated today. Current guidance advocates close monitoring and intervention in hyperglycaemia [9].

There are several limitations to this systematic review, primarily the limited body of studies relevant to our population; however, a review is only as good as the literature upon which it is based. There is a high level of bias for some of the included trials, with concerns related to funding. Bias, reliability and the small size of studies may affect validity of many of the trials available [50]. There are also many different outcome measures across the trials; these often are non-comparable due to different interventions or comparators, e.g. HAIs, making pooling difficult. There may also be differences in the preparation of PN used, and the calculations used to estimate caloric need 
[51], leading to variation in the interventions and subsequent outcomes [52]. However, the review is a robust systematic review that was conducted methodically with reference to the Cochrane handbook, and used best practice bias assessment with Cochrane Risk of Bias tool and GRADE PRO. Whilst it does not tell us clearly that PN is of significant value vs no nutrition, it does highlight that further research is required.

The outcomes reported in this review-mortality, hospital-acquired infections and length of stay-are important for patients and clinicians alike. PN is a mechanistically plausible intervention to improve these outcomes in the critically ill surgical patient. There is uncertainty about the true effect of PN in this population, meaning there is a clear need for randomised controlled trials. Key questions that research should answer include (i) whether PN offers benefit to the patient group compared to no nutrition support, (ii) whether early PN (e.g. $<24 \mathrm{~h}$ from admission) is better than delayed PN (e.g. 5 days or more after admission), (iii) whether glutamine supplementation offers clear benefit to this patient group, and (iv) what are the characteristics of patients who might benefit from these interventions. These studies should use patient and clinician important outcomes (e.g. quality of life, complications) rather than mechanistic outcomes (e.g. nitrogen balance) to determine if they are of tangible benefit.

\section{Conclusions}

In critically ill surgical patients, the use of PN may offer benefit in key outcomes. The size and quality of the studies lead to considerable uncertainty around the estimates of clinical effect, meaning a large-scale randomised controlled trial is required.

Acknowledgements The authors are grateful to Adele Sayers and Stephen Chapman for their constructive feedback on the manuscript.

Funding No funding was received for this study.

\section{Compliance with ethical standards}

Conflict of interest The authors declare that they have no conflict of interest.

Ethical approval The manuscript does not contain clinical studies or patient data.

Informed consent Informed consent is not required.

Open Access This article is distributed under the terms of the Creative Commons Attribution 4.0 International License (http://creativeco mmons.org/licenses/by/4.0/), which permits unrestricted use, distribution, and reproduction in any medium, provided you give appropriate credit to the original author(s) and the source, provide a link to the Creative Commons license, and indicate if changes were made.

\section{References}

1. Ahrens CL, Barletta JF, Kanji S et al (2005) Effect of low-calorie parenteral nutrition on the incidence and severity of hyperglycemia in surgical patients: a randomized, controlled trial. Crit Care Med 33:2507-2512. https://doi.org/10.1097/01.CCM.0000186746 $.64572 .8 \mathrm{~A}$

2. Buchman AL, Ament ME, Sohel M et al (2001) Choline deficiency causes reversible hepatic abnormalities in patients receiving parenteral nutrition: proof of a human choline requirement: a placebo-controlled trial. JPEN. https://doi.org/10.1177/01486 07101025005260 (Adolph M, Eckart A, Eckart J (1995). Fruct)

3. Buzby GP, Colling CL, Crosb LO, Al E (1991) Perioperative total parenteral nutrition in surgical patients. N Engl J Med 325:525532. https://doi.org/10.1056/NEJM199108223250801

4. Drover JW, Cahill NE, Kutsogiannis J et al (2015) Nutrition therapy for the critically ill surgical patient: we need to do better! JPEN 34:644-652. https://doi.org/10.1177/0148607110372391

5. Wolthuis AM, Bislenghi G, Fieuws S et al (2016) Incidence of prolonged postoperative ileus after colorectal surgery: a systematic review and meta-analysis. Colorectal Dis 18:O1-O9. https:// doi.org/10.1111/codi.13210

6. ESCP Intestinal Failure Group (2016) European Society of Coloproctology consensus on the surgical management of intestinal failure in adults. Color Dis 18:535-548. https://doi.org/10.1111/ codi. 13321

7. NICE (2006) Clinical Guideline 32: Nutrition support for adults: oral nutrition support, enteral tube feeding and parenteral nutrition. https://www.nice.org.uk/guidance/cg32. Accessed 12 Nov 2018

8. Singer P, Berger MM, Van den Berghe G et al (2009) ESPEN guidelines on parenteral nutrition: intensive care. Clin Nutr 28:387-400. https://doi.org/10.1016/j.clnu.2009.04.024

9. McClave SA, Taylor BE, Martindale RG et al (2016) Guidelines for the provision and assessment of nutrition support therapy in the adult critically Ill patient: Society of Critical Care Medicine (SCCM) and American Society for Parenteral and Enteral Nutrition (A.S.P.E.N.). J Parenter Enter Nutr 40:159-211. https://doi. org/10.1177/0148607115621863

10. Gunst J, Van den Berghe G (2017) Parenteral nutrition in the critically ill. Curr Opin Crit Care 23:149-158

11. The Veterans Affairs Total Parenteral Nutrition Cooperative Study Group (1992) Perioperative total parenteral nutrition in surgical patients. N Engl J Med 327:70-75. https://doi.org/10.1056/ NEJM199207093270202

12. NASBO (2017) Annual report of the national audit of small bowel obstruction 2017. http://nasbo.org.uk/wp-content/uploa ds/2017/11/NASBO-web.pdf. Accessed 12 Nov 2018

13. Higgins JPT, Green S (eds) (2011) Cochrane handbook for systematic reviews of interventions version 5.1.0 [updated March 2011]. The Cochrane Collaboration. Available from http://www. handbook.cochrane.org/

14. Knobloch K, Yoon U, Vogt PM (2011) Preferred reporting items for systematic reviews and meta-analyses (PRISMA) statement and publication bias. J Cranio-Maxillofac Surg 39:91-92. https:// doi.org/10.1016/j.jcms.2010.11.001

15. Tessari P (2006) In: Mantovani G, Anker SD, Inui A et al (eds) Nitrogen balance and protein requirements: definition and measurements BT-cachexia and wasting: a modern approach. Springer Milan, Milano, pp 73-79 
16. Schünemann H, Brożek J, Guyatt G, Oxman A (eds) (2013) GRADE handbook for grading quality of evidence and strength of recommendations. Updated October 2013. The GRADE Working Group, 2013. Available from https://guidelinedevelopment.org/ handbook

17. Antébi H, Mansoor O, Ferrier C et al (2004) Liver function and plasma antioxidant status in intensive care unit patients requiring total parenteral nutrition: comparison of 2 fat emulsions. J Parenter Enter Nutr 28:142-148

18. Estívariz CF, Griffith DP, Luo M et al (2008) Efficacy of parenteral nutrition supplemented with glutamine dipeptide to decrease hospital infections in critically ill surgical patients. JPEN J Parenter Enter Nutr 32:389-402. https://doi.org/10.1177/0148607108 317880

19. Goeters C, Wenn A, Mertes N et al (2002) Parenteral L-alanylL-glutamine improves 6-month outcome in critically ill patients. Crit Care Med 30:2032-2037. https://doi.org/10.1097/01. CCM.0000025908.95498.A3

20. Hulsewé KWE, van Acker BAC, Hameeteman W et al (2004) Does glutamine-enriched parenteral nutrition really affect intestinal morphology and gut permeability? Clin Nutr 23:1217-1225. https://doi.org/10.1016/j.clnu.2004.04.002

21. Jiang ZM, Cao JD, Zhu XG et al (1999) The impact of alanyl-glutamine on clinical safety, nitrogen balance, intestinal permeability, and clinical outcome in postoperative patients: a randomized, double-blind, controlled study of 120 patients. J Parenter Enter Nutr 23:S62-S66. https://doi.org/10.1177/014860719902300516

22. Powell-Tuck J, Jamieson C, Bettany GE et al (1999) A double blind, randomised, controlled trial of glutamine supplementation in parenteral nutrition. Gut 45:82-88

23. Luo M, Fernandez-Estivariz C, Jones DP et al (2008) Depletion of plasma antioxidants in surgical intensive care unit patients requiring parenteral feeding: effects of parenteral nutrition with or without alanyl-glutamine dipeptide supplementation. Nutrition 24:37-44. https://doi.org/10.1016/j.nut.2007.10.004

24. Wang X-Y, Li N, Gu J et al (2003) The effects of the formula of amino acids enriched BCAA on nutritional support in traumatic patients. World J Gastroenterol 9:599-602

25. Ziegler TR, May AK, Hebbar G et al (2016) Efficacy and safety of glutamine-supplemented parenteral nutrition in surgical ICU patients. Ann Surg 263:646-655. https://doi.org/10.1097/ SLA.0000000000001487

26. Hu Q-G, Zheng Q-C (2003) The influence of enteral nutrition in postoperative patients with poor liver function. World J Gastroenterol 9:843-846

27. Malhotra A, Mathur AK, Gupta S et al (2004) Early enteral nutrition after surgical treatment of gut perforations: a prospective randomised study. J Postgrad Med 50:102-106

28. Chen Z, Lin S, Dai Q et al (2017) The effects of pre-operative enteral nutrition from nasal feeding tubes on gastric outlet obstruction. Nutrients 9:373. https://doi.org/10.3390/nu9040373

29. Berard M, Pelletier A, Ollivier J et al (2002) Qualitative manipulation of amino acid supply during total parenteral nutrition in surgical patients. J Parenter Enter Nutr 26:136-143. https://doi. org/10.1177/0148607102026002136

30. Falk Delgado A, Falk Delgado A (2017) The association of funding source on effect size in randomized controlled trials: 20132015-a cross-sectional survey and meta-analysis. Trials 18:125. https://doi.org/10.1186/s13063-017-1872-0

31. Elke G, van Zanten ARH, Lemieux M et al (2016) Enteral versus parenteral nutrition in critically ill patients: an updated systematic review and meta-analysis of randomized controlled trials. Crit Care 20:117. https://doi.org/10.1186/s13054-016-1298-1

32. Wischmeyer PE, Hasselmann M, Kummerlen C et al (2017) A randomized trial of supplemental parenteral nutrition in underweight and overweight critically ill patients: the TOP-UP pilot trial. Crit Care 21:142. https://doi.org/10.1186/s13054-017-1736-8

33. Tamiya H, Yasunaga H, Matusi H et al (2015) Comparison of short-term mortality and morbidity between parenteral and enteral nutrition for adults without cancer: a propensity-matched analysis using a national inpatient database. Am J Clin Nutr 102:12221228. https://doi.org/10.3945/ajcn.115.111831

34. Bally MR, Blaser Yildirim PZ, Bounoure L et al (2016) Nutritional support and outcomes in malnourished medical inpatients: a systematic review and meta-analysis. JAMA Intern Med 176:4353. https://doi.org/10.1001/jamainternmed.2015.6587

35. Fuentes-Carrasco M, de Anda GV, Denova-Gutierrez E (2008) P019 nutritional support in critically ill patients decreases the length of stay and the mortality rate in the ICU. Clin Nutr Suppl 3:37. https://doi.org/10.1016/S1744-1161(08)70081-4

36. Jie B, Jiang Z-M, Nolan MT et al (2012) Impact of preoperative nutritional support on clinical outcome in abdominal surgical patients at nutritional risk. Nutrition 28:1022-1027. https://doi. org/10.1016/j.nut.2012.01.017

37. van Stijn MFM, Ligthart-Melis GC, Boelens PG et al (2008) Antioxidant enriched enteral nutrition and oxidative stress after major gastrointestinal tract surgery. World J Gastroenterol 14:69606969. https://doi.org/10.3748/wjg.14.6960

38. Abilés JS, Pérez R, Castaño J et al (2008) P020 effects of supply with glutamine on antioxidant system in patients with parenteral nutrition. Clin Nutr Suppl 3:37. https://doi.org/10.1016/S1744 $-1161(08) 70082-6$

39. Ziegler TR, Bazargan N, Leader LM, Martindale RG (2000) Glutamine and the gastrointestinal tract. Curr Opin Clin Nutr Metab Care 3:355-362

40. Matés JM, Pérez-gómez C, Núñez I et al (2002) Glutamine and its relationship with intracellular redox status, oxidative stress and cell proliferation/death. Int J Biochem Cell Biol 34:439-458

41. van Zanten ARH, Hofman Z, Heyland DK (2015) Consequences of the REDOXS and METAPLUS trials: the end of an era of glutamine and antioxidant supplementation for critically ill patients? JPEN J Parenter Enteral Nutr 39:890-892. https://doi. org/10.1177/0148607114567201

42. Wischmeyer P (2015) Glutamine supplementation in parenteral nutrition and Intensive Care Unit patients. J Parenter Enter Nutr 39:893-897. https://doi.org/10.1177/0148607115593792

43. Asrani V, Chang W, Dong Z et al (2013) Glutamine supplementation in acute pancreatitis: a meta-analysis of randomized controlled trials. Pancreatology 13:468-474

44. Schaible UE, Kaufmann SHE (2007) Malnutrition and infection: complex mechanisms and global impacts. PLoS Med 4:08060812. https://doi.org/10.1371/journal.pmed.0040115

45. Unosson M, Ek AC, Bjurulf P, Larsson J (1990) Effect of dietary supplement on functional parameters in geriatric patients. Clin Nutr 9:42. https://doi.org/10.1016/0261-5614(90)90274-V

46. Asprer JM, Llido LO, Sinamban R et al (2009) Effect on immune indices of preoperative intravenous glutamine dipeptide supplementation in malnourished abdominal surgery patients in the preoperative and postoperative periods. Nutrition 25:920-925. https ://doi.org/10.1016/j.nut.2009.01.014

47. Aghaeepour N, Kin C, Ganio EA et al (2017) Deep immune profiling of an arginine-enriched nutritional intervention in patients undergoing surgery. J Immunol. https://doi.org/10.4049/jimmu nol.1700421

48. Beier-Holgersen R, Brandstrup B (1999) Influence of early postoperative enteral nutrition versus placebo on cell-mediated immunity, as measured with the Multitest ${ }^{\circledR}$ CMI. Scand J Gastroenterol 34:98-102. https://doi.org/10.1080/00365529950172907

49. Van den Berghe G, Wilmer A, Germans G et al (2003) Intensive insulin therapy in the medical ICU. N Engl J Med 354:449-461. https://doi.org/10.1056/NEJMoa1109400 
50. Faber J, Fonseca LM (2014) How sample size influences research outcomes. Dental Press J Orthod 19:27-29. https://doi. org/10.1590/2176-9451.19.4.027-029.ebo

51. Fraipont V, Preiser J-C (2013) Energy estimation and measurement in critically ill patients. JPEN J Parenter Enter Nutr $37: 705-713$
52. Alberda C, Gramlich L, Jones N et al (2009) The relationship between nutritional intake and clinical outcomes in critically ill patients: results of an international multicenter observational study. Intensive Care Med 35:1728-1737. https://doi.org/10.1007/ s00134-009-1567-4 